\title{
Intensity-modulated radiation therapy for nasopharyngeal carcinoma: a review
}

\author{
Tony J. C. Wang $\cdot$ Nadeem Riaz $\cdot$ Simon K. Cheng $\cdot$ \\ Jiade J. Lu • Nancy Y. Lee
}

Received: 31 March 2012 / Accepted: 10 April 2012 / Published online: 24 May 2012

(C) Springer-Verlag 2012

\begin{abstract}
Introduction Advances in radiation therapy, such as intensity-modulated radiation therapy (IMRT), have allowed high-dose delivery to tumors while sparing normal tissues. However, IMRT requires careful delineation of target volumes to prevent marginal recurrences.

Results and discussion This review discusses the recent advances in the treatment of nasopharyngeal carcinoma with particular emphasis on IMRT. Multiple phase III trials that have relied on conventional radiotherapy have shown a survival benefit to concurrent chemoradiotherapy (CCRT) over radiotherapy (RT) alone. Two randomized trials using IMRT have demonstrated decreased xerostomia rates compared to conventional radiotherapy while still maintaining excellent local control rates, although follow-up was short. While modern locoregional results are excellent, $90 \%$ or more, distant-metastasis-free rates are not as impressive, ranging from 66 to $93 \%$ among studies.

Conclusion IMRT is an advanced technique, its excellent treatment outcomes have been reproduced in many single institution studies. Perhaps IMRT-delivered RT can replace the benefit provided by chemotherapy when added to
\end{abstract}

\section{T. J. C. Wang $\cdot$ S. K. Cheng}

Department of Radiation Oncology,

College of Physicians and Surgeons, Columbia University,

New York, NY, USA

\section{N. Riaz $\cdot$ N. Y. Lee $(\bowtie)$}

Department of Radiation Oncology,

Memorial Sloan-Kettering Cancer Center,

1275 York Avenue,

New York, NY 10065, USA

e-mail: leen2@mskcc.org

\section{J. J. Lu}

Department of Radiation Oncology, National University Hospital,

Singapore, Singapore conventional RT. Future studies should focus on reducing target volumes to minimize toxicity while dose-escalating for high-risk patients.

Keywords Intensity-modulated radiation therapy · Nasopharyngeal carcinoma $\cdot$ Radiotherapy

\section{Introduction}

Nasopharyngeal carcinoma (NPC) can be difficult to treat because the nasopharynx is surrounded by many sensitive normal structures. Improved treatment has led to many patients living for decades after diagnosis and increased the importance of minimizing side effects. The development of new radiotherapy (RT) techniques has facilitated minimizing complications and late sequellae of treatment.

Intensity-modulated radiation therapy (IMRT) is a technique that allows the modification of each radiation beam, whether by shaping the field or changing the dose-intensity, and provides highly conformal dose delivery. This permits high-dose delivery to the tumor while simultaneously reducing dose to the normal tissues. It is commonly performed by using inverse planning which allows a computer to suggest a plan based on predetermined target dose parameters that the responsible physician finds clinically acceptable. The benefit of IMRT comes with a potential drawback in that as dose to the target volumes become more conformal, incorrect delineation of the target or normal structures can cause marginal or complete misses. Therefore, accurate delineation of target volumes and critical normal structures for IMRT is crucial. While clinical studies that demonstrate clinicians' abilities to do this reliably are just beginning to appear, dosimetric studies of IMRT for NPC have reported improved tumor coverage and normal tissue sparing [1-3]. 
Recent clinical studies, including two phase III trials, have demonstrated improved protection of salivary function using IMRT [4-6]. Subject to future studies, IMRT has become the gold standard means of delivering radiation therapy for NPC. This article therefore reviews recent advances in the treatment of NPC based on IMRT.

\section{Intensity-modulated radiation therapy vs. older techniques}

One of the biggest challenges of treating NPC using conventional techniques is to prescribe a tumoricidal dose to gross disease without causing clinically important toxicity in normal structures. Two-dimensional RT (2D-RT), typically with opposed lateral portals, did not permit equivalent sparing of normal structures without under-treating gross disease. Common toxicities with this technique, particularly with concurrent chemotherapy, included: xerostomia, occurring in over $90 \%$ of patients and $70 \%$ have reported moderate or severe symptoms [7, 8], mucositis, where significant mucositis have been reported from 33 to $64 \%$ of patients [9-11], and dysphagia, where the most common dysfunction was pharyngeal retention ranging from 77 to $93.5 \%$ [12-14]. Two-year locoregional recurrence rates ranged from 13 to $26.6 \%$ and 5 -year survival rates ranged from 43.5 to $70.6 \%$ [15]. Threedimensional conformal RT (3D-RT) was an improvement over 2D-RT, but still had difficulty covering the target when it was close to critical structures such as the brainstem. The benefit of IMRT over 2D-RT or 3D-RT is that it can improve coverage to disease while reducing dose to adjacent organs.

\section{Dosimetric advantages of IMRT}

Several institutions have shown an unquestionable dosimetric benefit of IMRT for NPC over conventional techniques $[1,3]$. Hunt et al. showed that compared to 3D-RT, IMRT lowered doses to the spinal cord, mandible, and temporal lobes while increasing coverage to the retropharynx, skull base, and nodal regions [1]. Xia et al. compared IMRT, 3DRT, and 2D-RT plans for locally advanced NPC [3]. They found that IMRT was able to achieve the same dose coverage to the target volume, while reducing dose to the parotid gland, optic chiasm, and brainstem.

An additional dosimetric advantage of IMRT is simultaneous delivery of different doses during every fraction of treatment. This can allow areas of subclinical disease to receive adequate lower doses compared to gross disease where doses can be substantially higher. This technique has been referred to in the literature by a variety of terms including simultaneous integrated boost, simultaneous modulated accelerated RT, or dose painting [16-18].

\section{Clinical advantages of IMRT}

Lee et al. reported one of the earliest clinical experiences of IMRT for NPC [19]. With a median follow-up of 31 months, the 4-year local progression-free rate was $97 \%$ and the 4year locoregional progression-free rate was $98 \%$. Furthermore, these excellent outcomes occurred despite the fact that the majority of these patients ( $70 \%$ ) had locally advanced disease. Subsequently, several institutions have reported their IMRT experience with similar outcomes. A prospective study from Hong Kong using IMRT alone for early-stage NPC reported a 3-year local control, distant metastases free, and overall survival rate of $100 \%$ [20]. Kam et al. reported a 3 -year local relapse-free survival rate of $92 \%$ and 3-year nodal relapse-free survival rate of $98 \%$ [21]. This study was similar to Lee et al. [19] in that the majority of patients $(57 \%)$ presented with locally advanced disease. Wolden et al. reported 3-year local control rates of $91 \%$ and 3-year regional control rates of $93 \%$, of which $77 \%$ of patients presented with stage III and IV disease [22]. Kwong et al. reported dose escalation results using IMRT for stage III and IV NPC [23]. The 2-year locoregional control rate was $95.7 \%$. Additional results of published IMRT series are summarized in Table 1.

Two phase III trials compared IMRT vs. conventional RT for early-stage NPC. Pow et al. [6] reported that IMRT was significantly better than conventional RT in regards to parotid sparing and improved quality of life. Kam et al. [4] showed that the incidence of observer-rated xerostomia was $39.4 \%$ with IMRT compared to $82.1 \%$ with conventional RT $(p=0.01)$. Furthermore, patients who received IMRT had higher stimulated whole saliva flow rate and stimulated parotid flow rate. It is important to note that there was no statistical difference in patient-reported outcomes of xerostomia. Improvement in observer-rated xerostomia was not closely associated with patient-reported outcomes emphasizing the importance of monitoring both measured and patient-reported assessments. Similarly in Radiation Therapy Oncology Group (RTOG) 0225, which was a phase II study of IMRT with or without chemotherapy for NPC of all stages, the investigators were able to demonstrate the feasibility of delivering IMRT in a multi-institutional setting with reproducible excellent outcomes [5]. At 1 year from start of IMRT, only $13.5 \%$ of patients had grade 2 xerostomia. For all patients, only two patients complained of grade 3 xerostomia and none had grade 4 xerostomia.

Since IMRT reduces toxicity compared to older techniques, it may increase patient compliance to chemoradiation. In RTOG $0225,90 \%$ of patients received the planned 70 Gy and $88 \%$ with locally advanced disease received three cycles of concurrent cisplatin [5]. This compliance rate compared favorably to $63 \%$ in the Intergroup 0099 trial, $52 \%$ in the Hong Kong NPC-9901 trial, and $71 \%$ in the 
Table 1 Results from series treating NPC with IMRT with or without chemotherapy

\begin{tabular}{|c|c|c|c|c|c|c|c|c|c|}
\hline Study & Year & Stage & No. & $\begin{array}{l}\text { Median follow-up } \\
\text { (months) }\end{array}$ & $\begin{array}{l}\text { Time point } \\
\text { (years) }\end{array}$ & $\begin{array}{l}\text { Local control } \\
\text { rate }(\%)\end{array}$ & $\begin{array}{l}\text { Regional control } \\
\text { rate }(\%)\end{array}$ & $\begin{array}{l}\text { Distant met-free } \\
\text { rate }(\%)\end{array}$ & $\begin{array}{l}\text { OS } \\
(\%)\end{array}$ \\
\hline Lee et al. [19] (UCSF) & 2002 & All & 67 & 31 & 4 & 97 & 98 & 66 & 88 \\
\hline Kwong et al. [20] (Hong Kong) & 2004 & $\mathrm{~T} 1 \mathrm{~N} 0-1^{\mathrm{a}}$ & 33 & 24 & 3 & 100 & 92 & 100 & 100 \\
\hline Kam [21] (Hong Kong) & 2004 & All & 63 & 29 & 3 & 92 & 98 & 79 & 90 \\
\hline Wolden et al. [22] (MSKCC) & 2006 & All & 74 & 35 & 3 & 91 & 93 & 78 & 83 \\
\hline Kwong et al. [23] (Hong Kong) & 2006 & III-IVB ${ }^{\mathrm{a}}$ & 50 & 25 & 2 & 96 & NA & 94 & 92 \\
\hline RTOG 0225 [5] & 2009 & All & 68 & 31 & 2 & 93 & 91 & 85 & 80 \\
\hline Tham et al. [32] (Singapore) & 2009 & All & 195 & 37 & 3 & 90 & NA & 89 & 94 \\
\hline Lin et al. [29] (China) & 2009 & II-IV ${ }^{\mathrm{a}}$ & 323 & 30 & 3 & 95 & 98 & 90 & 90 \\
\hline Wong et al. [33] (China) & 2010 & All & 175 & 34 & 3 & 94 & 93 & 87 & 87 \\
\hline Lin et al. [28] (China) & 2010 & IIB-IVB ${ }^{a}$ & 370 & 31 & 3 & 95 & 97 & 86 & 89 \\
\hline Kam et al. [57] (Hong Kong) & 2010 & All & 231 & 59 & 6 & 82 & 91 & 75 & 66 \\
\hline Ng et al. [30] (Hong Kong) & 2011 & All & 193 & 30 & 2 & 95 & 96 & 90 & 92 \\
\hline Xiao et al. [34] (China) & 2011 & III-IVA ${ }^{\mathrm{a}}$ & 81 & 54 & 5 & 95 & NA & NA & 75 \\
\hline Bakst et al [35] (MSKCC) & 2011 & II-IVB ${ }^{\mathrm{a}}$ & 25 & 33 & 3 & 91 & 91 & 91 & 89 \\
\hline Xiayun et al. [37] (China) & 2011 & IIB-IVB ${ }^{b}$ & 54 & 30 & 3 & 95 & 98 & 86 & 88 \\
\hline Ma et al. [36] (Hong Kong) & 2011 & III-IVB ${ }^{\mathrm{b}}$ & 30 & 32 & 2 & 93 & 93 & 93 & 90 \\
\hline RTOG 0615 [27] & 2012 & IIB-IVB ${ }^{c}$ & 42 & 30 & 2 & NA & NA & 91 & 91 \\
\hline Su et al. [31] (China) & 2012 & $\mathrm{I}-\mathrm{IIB}^{\mathrm{b}}$ & 198 & 51 & 5 & 97 & 98 & 98 & NA \\
\hline
\end{tabular}

NPC nasopharyngeal carcinoma, IMRT intensity-modulated radiation therapy, OS overall survival, UCSF University of California at San Francisco, $M S K C C$ Memorial Sloan-Kettering Cancer Center, RTOG Radiation Therapy Oncology Group, $N A$ not available, $T$ primary tumor stage

${ }^{a}$ AJCC Staging Manual 5th Edition [58]

${ }^{\mathrm{b}}$ AJCC Staging Manual 6th Edition [59]

${ }^{\mathrm{c}}$ AJCC Staging Manual 7th Edition [60]

Singapore randomized trial [24-26] all of which used nonIMRT techniques.

\section{Treatment planning and target volumes}

While IMRT is commonly used for many head and neck cancer sites, it is a tool that can be used at its full potential only if the technical aspects of treatment planning are well understood and the required methodology is disseminated throughout the Radiation Oncology community. This aspect of IMRT often receives the least attention in the literature, but may be the most important factor in achieving the results described above.

Based on a series of IMRT publications for NPC (Table 2), 13 studies have reported using treatment planning $\mathrm{CT}$ with $3 \mathrm{~mm}$ or less thickness [5, 20-23, 27-34], one study used 3 to $5 \mathrm{~mm}$ which may have been as a result of available technology at the time given that it was the first reported experience [19], while three studies did not report slice thickness [35-37]. Therefore, given the available data, we recommend using treatment planning CT with $3 \mathrm{~mm}$ or less thickness in areas that contain disease.

Fusion of MRI or PET scans with treatment planning CT images is highly encouraged to accurately delineate the target volumes. In the series listed on Table 2, all studies reported using MRI as part of pretreatment workup [5, 19-23, 27-37], among them, 13 studies either required or performed MRI on the vast majority of patients $(95 \%$ or more) $[5,19,20,23,27-30,32,33,35-37]$. MRI has been demonstrated to be better at showing tumor extent than CT and should be part of pretreatment planning [38, 39]. In addition, PET was used in eight studies [19, 22, 27-29, 32, $34,35]$, while the data was not available in nine studies $[19-21,23,30,31,33,36,37]$. Fused plans or coregistration was performed in ten studies $[5,21,22$, 27-30, 32, 33, 35].

The delineation of gross tumor volume (GTV) varies from institution to institution and we have summarized this in Table 2. In addition to the primary tumor, the GTV included nodes greater than $1 \mathrm{~cm}$ in diameter or nodes with necrotic center in four studies [5, 27, 33, 35]. In ten studies, the GTV also included involved lymph nodes without explicitly defining the criteria [19, 21, 22, 28-32, 34, 37]. Kwong et al. described the GTV as any macroscopic tumor and the whole nasopharynx, including bilateral Eustachian cushions and prevertebral muscles in one paper [20], while a subsequent paper described the GTV as the whole nasopharynx, tumor extending outside the nasopharynx, any skull 
base erosion, and intracranial disease as well as enlarged neck nodes [23]. The criteria for defining involved lymph nodes remain controversial as many studies did not define this explicitly. However, in general, all lymph nodes that are PET positive or greater than $1 \mathrm{~cm}$ in short axis should receive definitive treatment.

The clinical target volume (CTV) varies even more than GTV from between institutions, due to different methods of contouring, including the margin around the GTV and the delineation of high-risk volumes. From the studies listed on Table 2, the CTV margin around the GTV was $1 \mathrm{~cm}$ in three studies [20,21, 23], $0.5 \mathrm{~cm}$ or more in eight studies [5, $27-29,31-34]$, and $0.2 \mathrm{~cm}$ or more in one study [30]. Two studies that did not include CTV described using a PTV with $1 \mathrm{~cm}$ margin beyond the GTV [22, 35]. Among those that described CTV margins, seven studies described shrinking the posterior margin if the CTV was close to critical structures like the brainstem [5, 21, 23, 27, 31, 33, 34]. Two studies reduced a $1-\mathrm{cm}$ margin to $0.5 \mathrm{~cm}[21,23]$, two studies reduced $0.5-1 \mathrm{~cm}$ margin to $0.2-0.5 \mathrm{~cm}[31,34]$, and three studies reduced $\geq 0.5 \mathrm{~cm}$ margin to as small as $0.1 \mathrm{~cm}[5,27,33]$. Based on these results, many studies used a $0.5-\mathrm{cm}$ margin with an optional posterior margin reduction of $0.1-0.5 \mathrm{~cm}$.

The delineation of CTV for high-risk regions varies greatly from institution to institution and we have summarized a list of studies that define target volumes in Table 3. In general, the clivus, skull base, inferior sphenoid sinus, cavernous sinus, pterygoid fossae, parapharyngeal space, posterior nasal cavity and maxillary sinus, retropharyngeal lymph nodes, and levels II through V are covered. For the clivus, eight studies covered the anterior third to half of the clivus if there was no involvement [20, 21, 27-30, 32, 37]. If there is any involvement, the clivus should be covered entirely. For the base of skull, six studies included the petrous tips and/or the foramen ovale $[20,21,23,27,30$, 32]. One study also included the foramen rotundum [27]; while two studies included the foramen spinosum [20, 23]. Coverage of the inferior orbital fissure was described in two studies $[20,23]$ and the anterior third to half of the arch of cervical vertebrae 1 (C1) was covered in four studies [20, $23,28,29]$. Given the lack of data, it is unclear if the inferior orbital fissure or the anterior arch of $\mathrm{C} 1$ should be part of the CTV and this may be a potential area to spare. An example of delineation for GTV and CTV is shown in Fig. 1.

The greatest variability for cervical lymph node coverage is level I. In two studies, level Ia was covered electively if Ib nodes or the oral cavity was involved [21,32]. Three studies covered level $\mathrm{Ib}$ routinely $[5,21,33]$, three studies had the option to spare level Ib in N0 disease [27, 30, 32], and two studies did not cover level $\mathrm{Ib}[28,29]$. Based on the data, we do not recommend routinely covering level Ia. Additionally, level $\mathrm{Ib}$ is an area that may be potentially spared even with node positive disease. Two studies that did not cover level Ib reported 3-year locoregional control rates of 95-98 \% despite having $80 \%$ of patients with locally advanced disease $[28,29]$. For retropharyngeal lymph nodes, the inferior border is at the hyoid bone in two studies $[21,40]$ and at the cranial edge of the second cervical vertebrae in two studies [28, 29]. It is important to note that in the consensus guideline by Gregoire et al. [41], the inferior border of the retropharyngeal node is defined as the cranial edge of the body of the hyoid bone.

The planning target volume (PTV) margin also varies similarly to CTV margin and is listed in Table 2. The PTV margin off of CTV was $0.5 \mathrm{~cm}$ or more in four studies [5, $27,33,37], 0.3 \mathrm{~cm}$ in five studies [21, 28-30,32], and $0.2 \mathrm{~cm}$ in two studies $[20,23]$. In the two studies with $0.2 \mathrm{~cm}$ margin, the CTV margin beyond GTV was $1 \mathrm{~cm}$ which is relatively large [20,23]. There is no clear consensus on PTV margin but it is reasonable to use 0.3 to $0.5 \mathrm{~cm}$ based on the available data.

We list the studies that included organs at risk with dose constraints in Table 4. In general, the brainstem, spinal cord, eyes, optic nerves, chiasm, lens, temporal lobes, parotid glands, inner/middle ears, temporomandibular joints, mandible, oral cavity, and larynx are included. The dose constraints vary among institutions and there are few data that suggest one is superior to the others. The Quantitative Analysis of Normal Tissue Effects in the Clinic (QUANTEC) provides recent data behind normal tissue complication probabilities [42].

For the brainstem, the maximum dose (dmax) was 56 Gy in four studies [20, 23, 33, 34], 54 Gy in five studies [5, 21, $27,30,36]$, and $50 \mathrm{~Gy}$ in one study [32]. In four studies, $1 \%$ of the brainstem could not exceed 60 Gy $[5,27,30,33]$. For the spinal cord, the dmax was 50 Gy in one study [23], 46 Gy in one study [20], and 45 Gy in seven studies [5, 27, $30,32-34,36]$. In four studies, $1 \%$ or $1 \mathrm{cc}$ of the spinal cord could not exceed 50 Gy [5, 27, 30, 33]. For the eyes, the dmax was 58 Gy in two studies [20,23] and 50 Gy in two studies $[5,30]$. The mean dose (dmean) for the eyes was 50 Gy or less in two studies [20, 23] and 35 Gy or less in three studies [5, 30, 33]. The optic nerves and chiasm essentially have the same dose constraint. The dmax for the optic nerves and chiasm was 58 Gy in two studies [20, 23], 54 Gy in five studies [5, 21, 30, 33, 36], and 50 Gy in three studies [27, 32, 34]. The dmean was 50 Gy or less in two studies $[20,23]$ and two studies stated that $1 \%$ of optic nerve and chiasm could not exceed 60 Gy $[5,30]$. For the temporal lobes, the dmax was 67 Gy in one study [36], 65 Gy in one study [30], 60 Gy in four studies [5, 23, 33, 34], and 58 Gy in one study [20]. The dmean for the temporal lobes was 50 Gy or less in two studies [20, 23] and in three studies, $1 \%$ of the temporal lobes could not exceed 65 Gy [27, 30, 33]. 


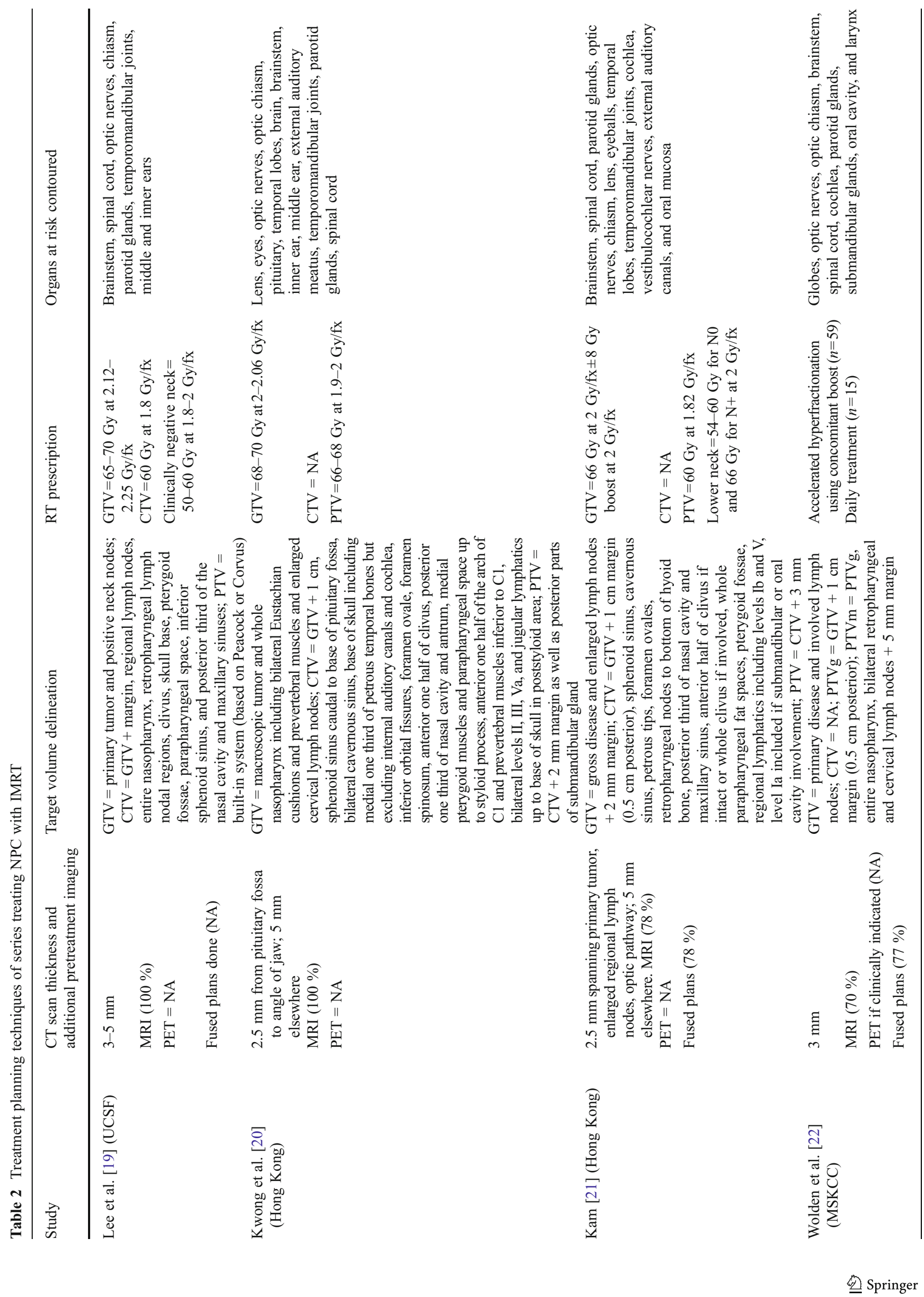




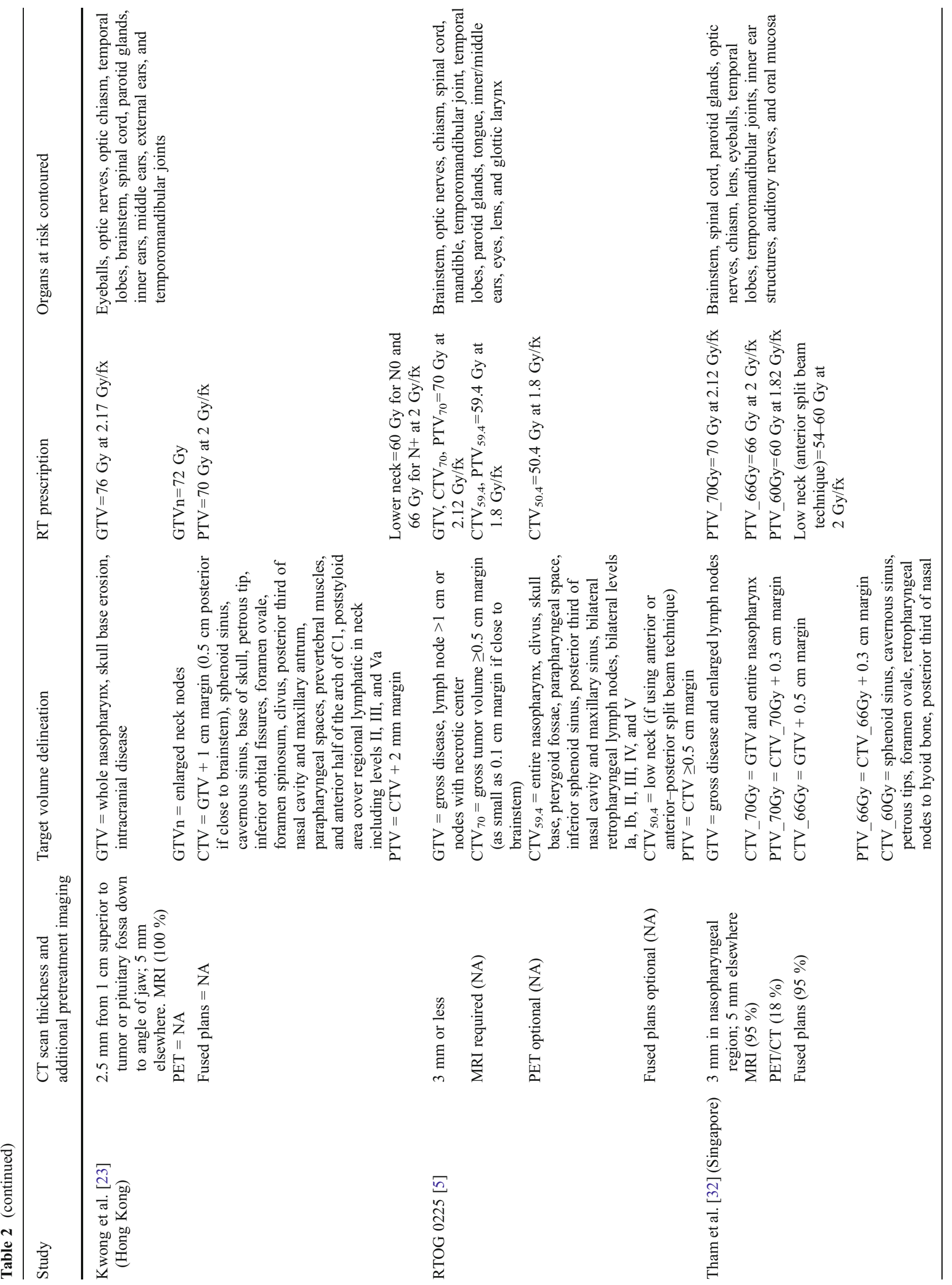




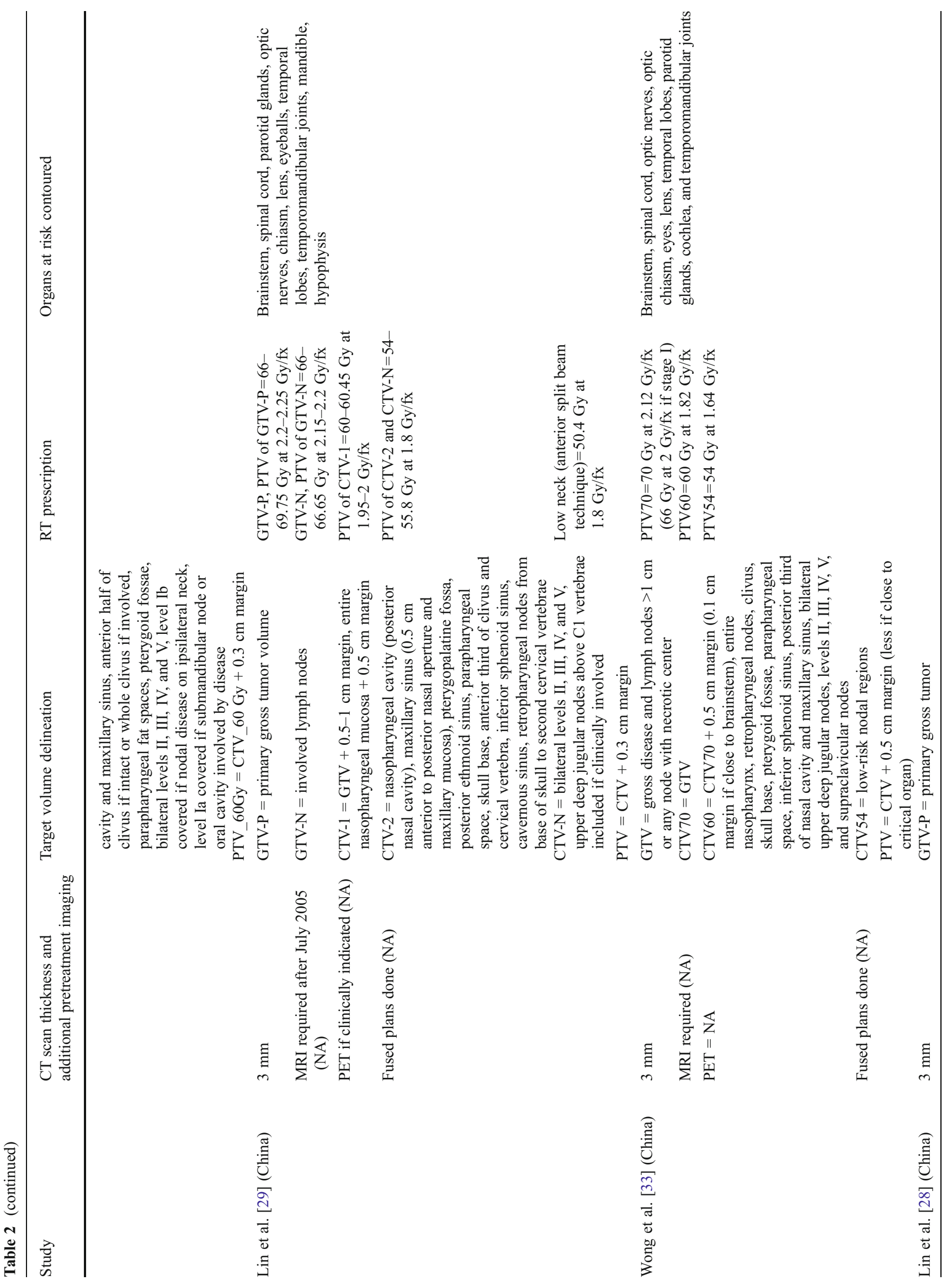




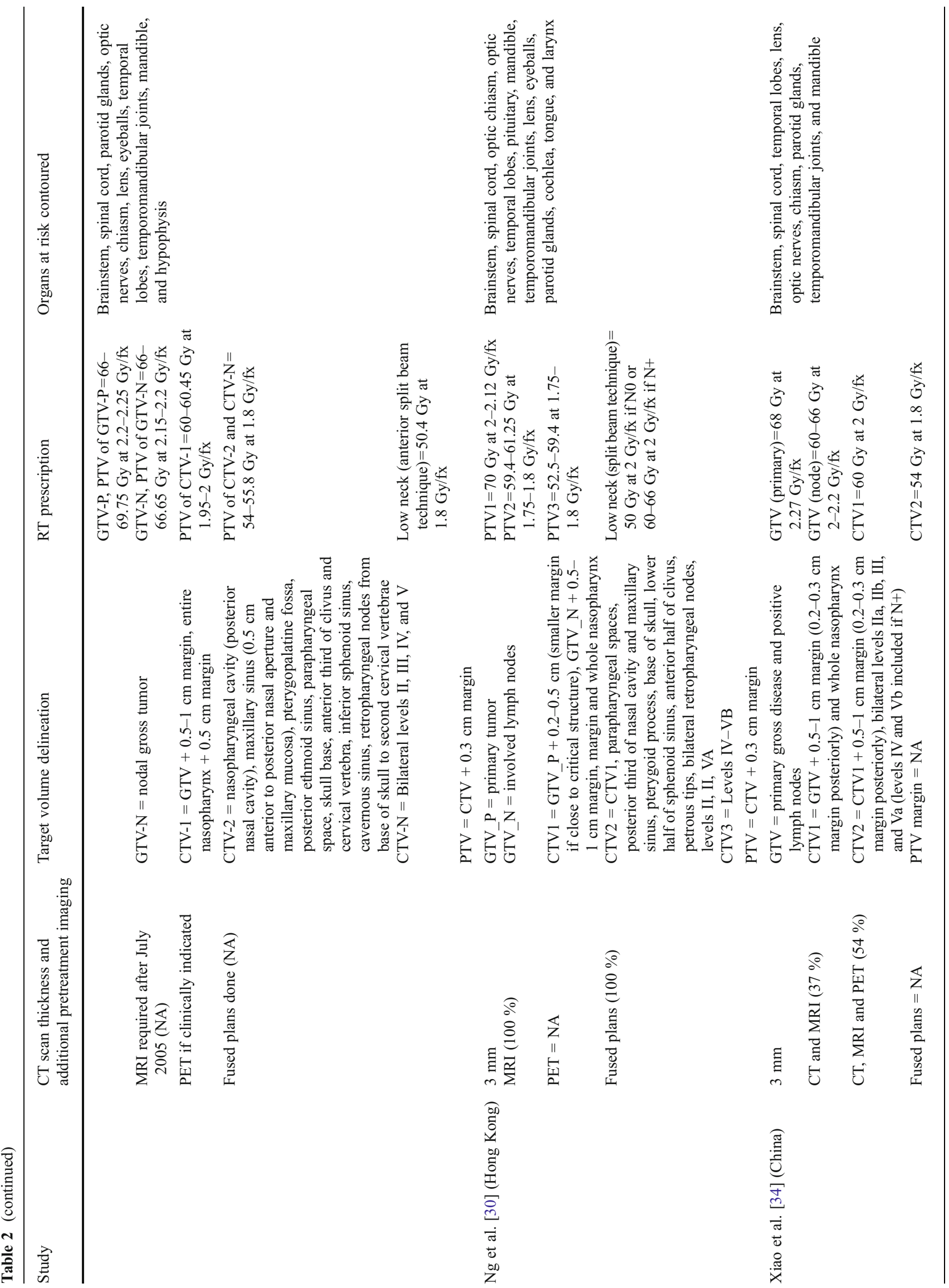




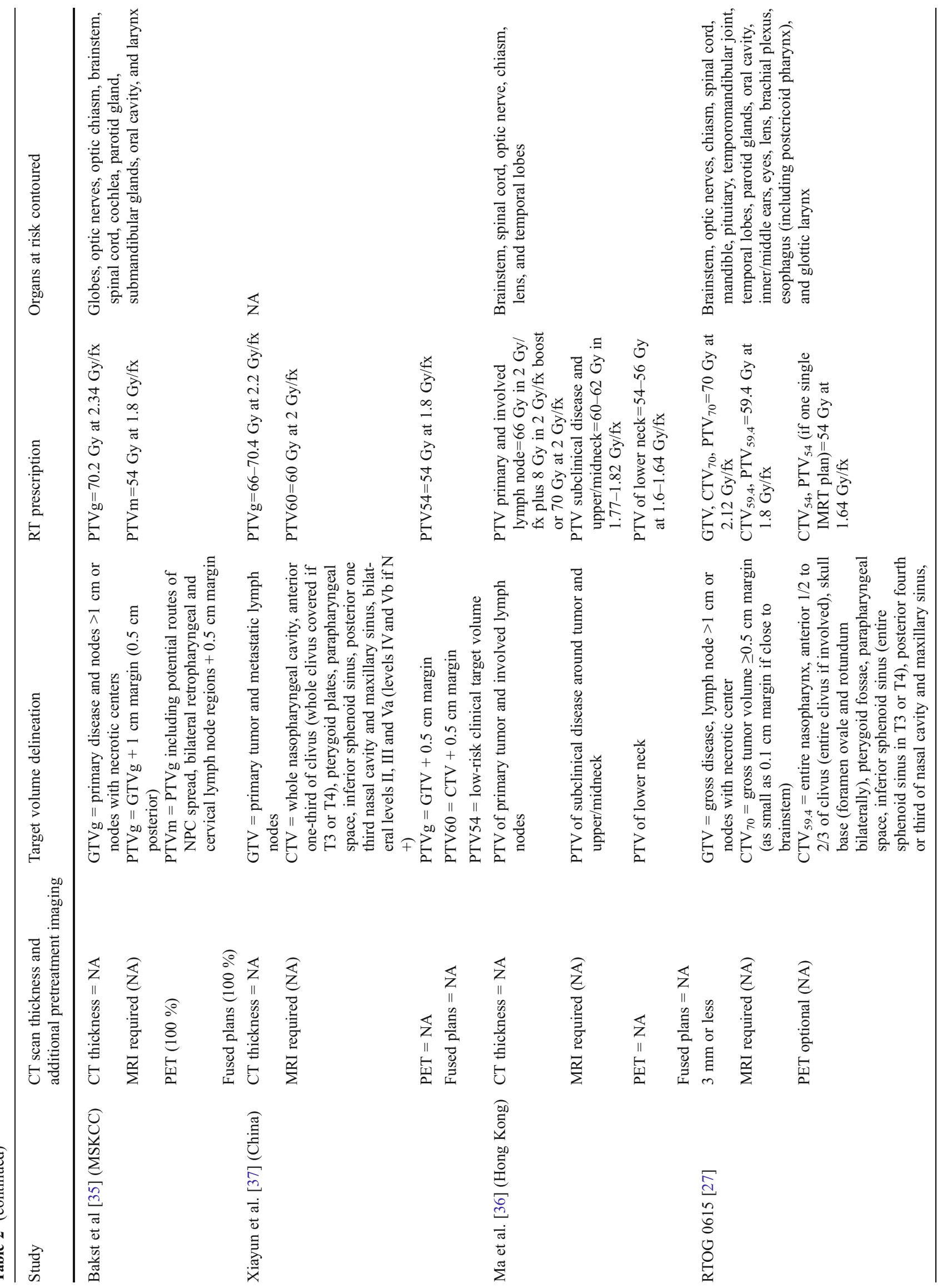




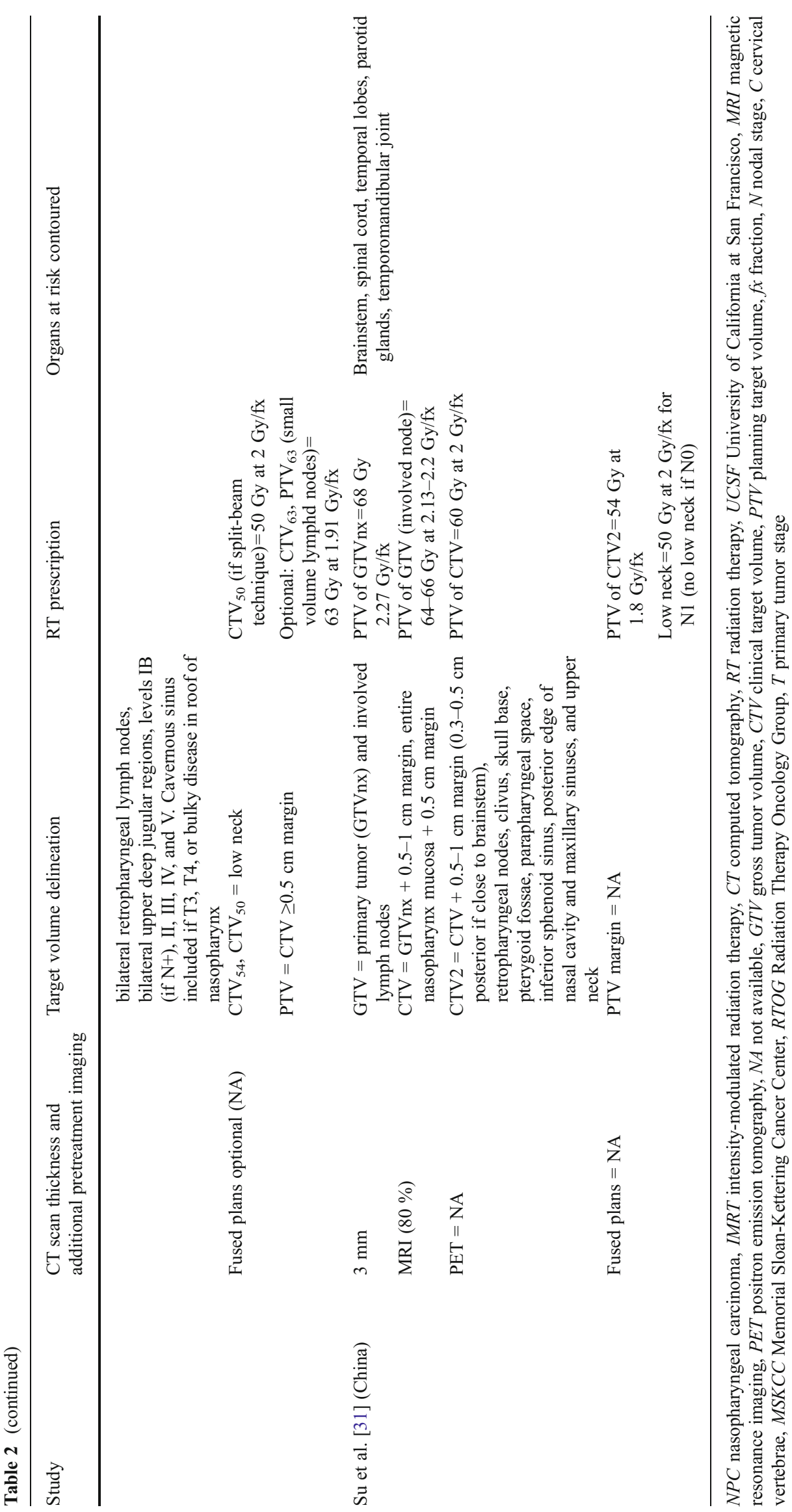




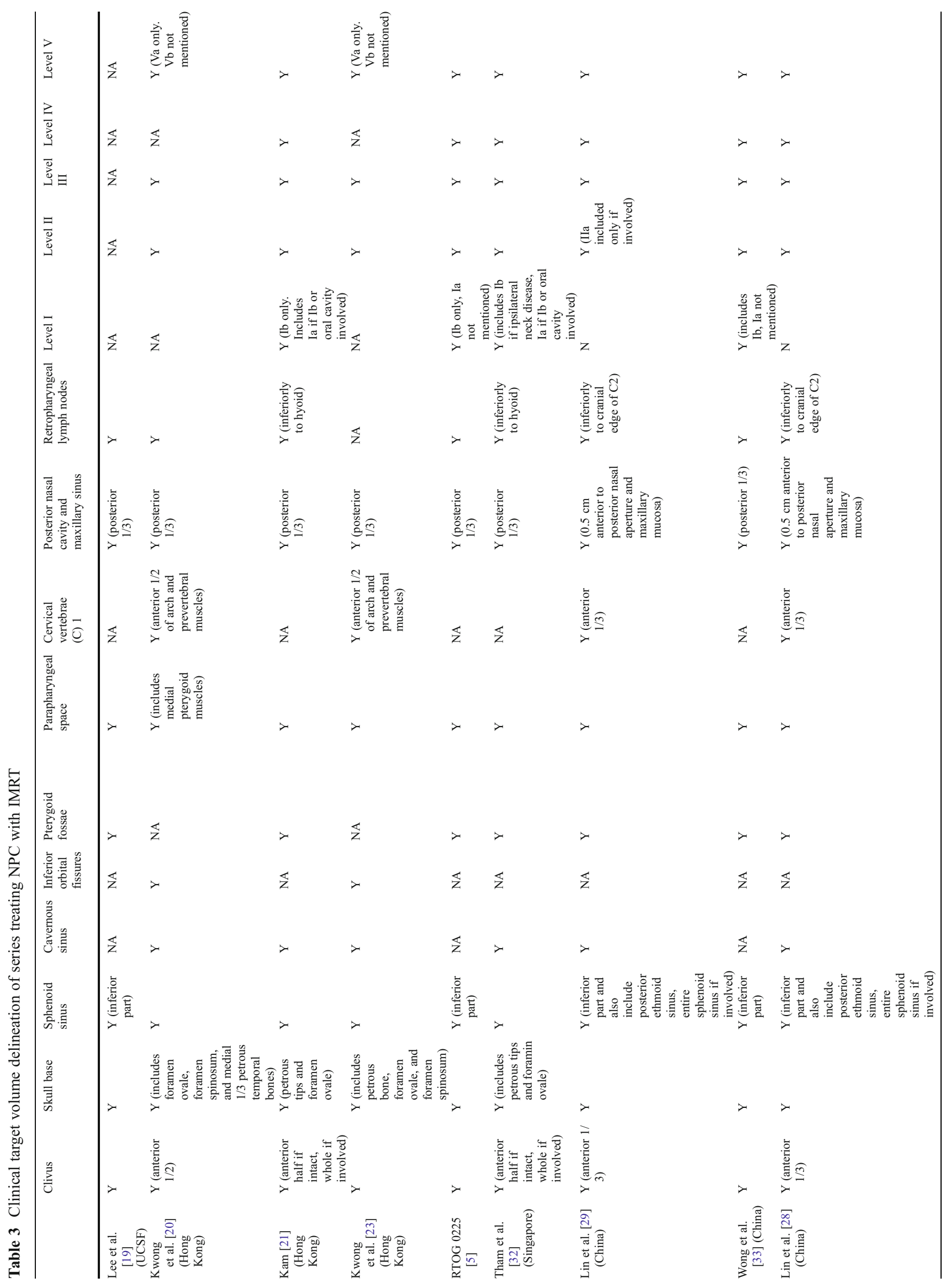



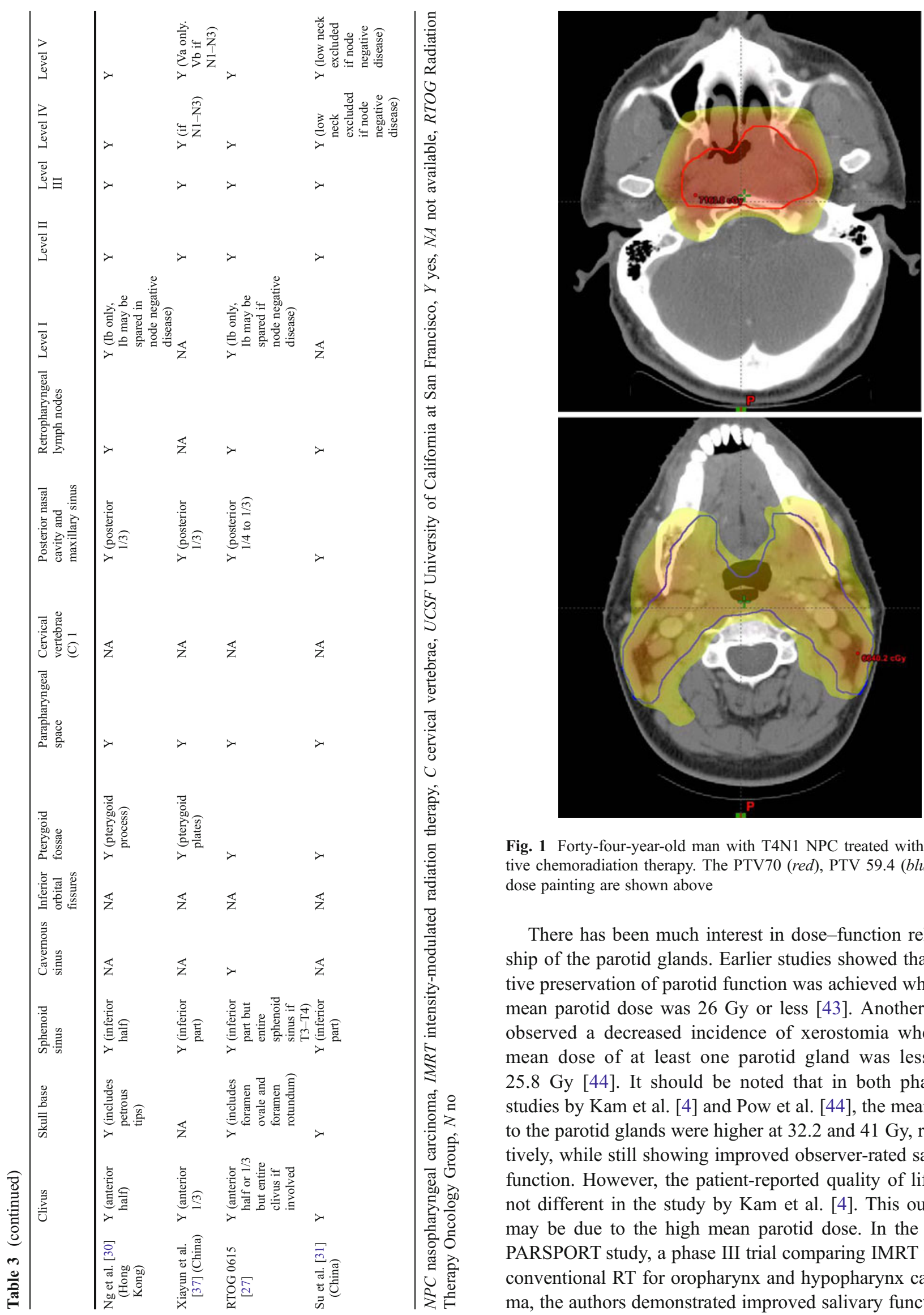

Fig. 1 Forty-four-year-old man with T4N1 NPC treated with definitive chemoradiation therapy. The PTV70 (red), PTV 59.4 (blue), and dose painting are shown above

There has been much interest in dose-function relationship of the parotid glands. Earlier studies showed that relative preservation of parotid function was achieved when the mean parotid dose was 26 Gy or less [43]. Another study observed a decreased incidence of xerostomia when the mean dose of at least one parotid gland was less than 25.8 Gy [44]. It should be noted that in both phase III studies by Kam et al. [4] and Pow et al. [44], the mean dose to the parotid glands were higher at 32.2 and $41 \mathrm{~Gy}$, respectively, while still showing improved observer-rated salivary function. However, the patient-reported quality of life was not different in the study by Kam et al. [4]. This outcome may be due to the high mean parotid dose. In the recent PARSPORT study, a phase III trial comparing IMRT versus conventional RT for oropharynx and hypopharynx carcino$\mathrm{ma}$, the authors demonstrated improved salivary function in 


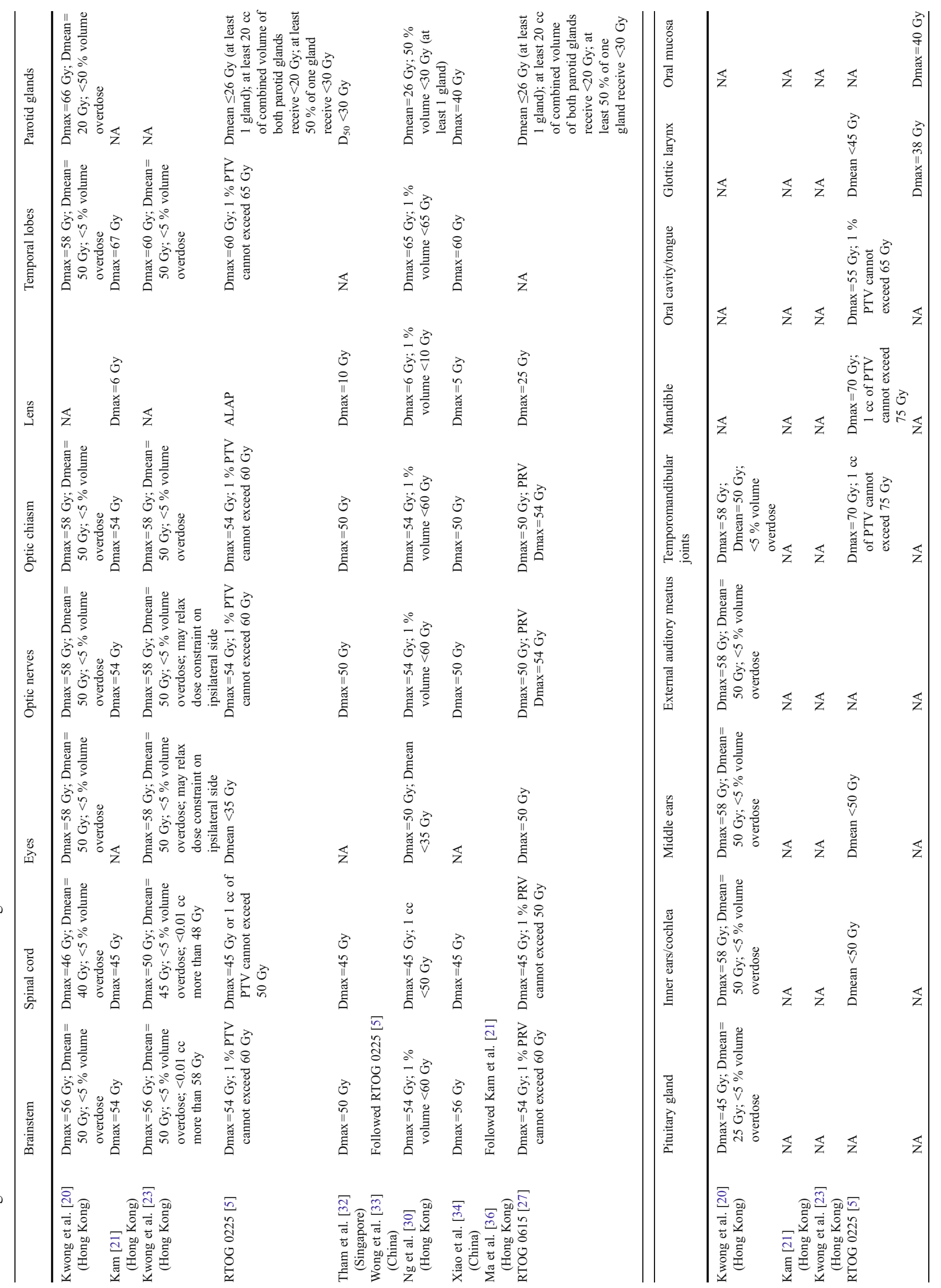


observer and patient-reported outcomes [45] Despite treating different sites, it is still interesting to find that while the mean ipsilateral parotid dose was $47.6 \mathrm{~Gy}$, the mean contralateral parotid dose was 25.4 Gy which may have attributed to the improved patient-reported quality of life.

\section{Early-stage nasopharyngeal carcinoma}

For stage I NPC, the standard treatment is RT alone. The location of the nasopharynx near critical structures makes surgical approaches limited. Historical long-term survival for early-stage NPC patients who received conventional RT alone ranged from 60-80 \% [46, 47]. A larger, modern study from Hong Kong reported 5-year local control and overall survival as high as 91 and $90 \%$, respectively, for early-stage NPC using predominantly conventional RT [48]. It is possible that the results were improved due to greater number of available linear accelerators and higher number of pretreatment MRIs. Because long-term xerostomia is a well-known problem after head and neck RT, investigators have looked into parotid-sparing techniques with IMRT. In 2004, Kwong et al. not only reported excellent results for early-stage NPC with IMRT but also showed progressive recovery of salivary function [20]. At 1 year after IMRT, 60 and $47 \%$ of patients recovered at least $25 \%$ of their baseline stimulated parotid salivary (SPS) flow and stimulated whole salivary (SWS) flow, respectively. By 2 years, SPS and SWS flow improved to 86 and $71 \%$, respectively.

In the previously mentioned phase III studies of early-stage NPC treated with IMRT, Kam et al. [4] and Pow et al. [6] were able to show no difference in local control while improving xerostomia. In addition, in RTOG 0225 [5], with a median follow-up of 2.6 years, no early-stage patients who were treated with IMRT alone developed locoregional failure. Thus, it seems fair to conclude that IMRT controls over $90 \%$ of stage I NPC and simultaneously protects the parotids to the degree that restoration of function can be expected in $50 \%$ of patients after 1 year.

\section{Intermediate-stage nasopharyngeal carcinoma}

For patients with stage II disease, there currently is too little data to be sure if RT alone is sufficient. A recent phase III study from China randomized 230 NPC patients with T1$2 \mathrm{~N} 1 \mathrm{M} 0$ or T2N0M0 disease with parapharyngeal space involvement to 2D-RT versus concurrent chemoradiotherapy (CCRT) [9]. Chemotherapy consisted of weekly cisplatin. With a median follow-up of 5 years, the study showed improvement in overall survival (95 vs $86 \%$ ), progressionfree survival ( 88 vs $78 \%$ ), and distant-metastasis-free 
survival ( 95 vs $84 \%$ ) of CCRT compared to 2D-RT while there was no significant difference in locoregional control (93 vs $91 \%$ ). However, it is important to be aware that in this trial all patients were treated using 2D-RT. Patients also did not have chest CT screening as part of their pretreatment evaluation, thus some pre-existing distant metastases may have been missed. Additionally, 31 patients (13\%) upon restaging to the 2010 AJCC staging system were reclassified as stage III.

While this study showed that CCRT is recommended for stage II disease treated with 2D-RT, it is important to consider whether chemotherapy is simply compensating for 2DRT since none of these patients were treated with IMRT. It is possible that IMRT may provide better locoregional control and therefore reduce or eliminate the benefit of chemotherapy. Perhaps a phase III trial using IMRT with or without concurrent chemotherapy for stage II NPC would be helpful in answering the question.

\section{Locally advanced nasopharyngeal carcinoma}

Intergroup 0099 was the first phase III study to establish CCRT as the standard of care for locally advanced NPC [24]. However, this study was questioned due to its poor results in the RT-only arm and its higher incidence of nonendemic histology. Subsequently, nine additional phase III randomized trials investigating RT versus CCRT with or without adjuvant chemotherapy have been published (Table 5) $[9,26,49-55]$. Of the ten trials, seven have shown an overall survival benefit with CCRT $[9,24,26,49,50,54$, 55]. A meta-analysis of eight randomized trials demonstrated that chemotherapy provided an absolute overall survival advantage of $6 \%$ at 5 years and that the benefit was greatest with concomitant chemotherapy while induction and adjuvant chemotherapy were inconclusive [56]. These studies have confirmed the benefit of CCRT as the treatment of choice for locally advanced NPC.

Table 5 Phase III trials comparing 2D-RT alone versus CCRT, with or without adjuvant chemotherapy

\begin{tabular}{|c|c|c|c|c|c|c|c|c|c|c|}
\hline Study & Year & Stage & $\begin{array}{l}\text { Median } \\
\text { follow-up } \\
\text { (months) }\end{array}$ & $\begin{array}{l}\text { Time } \\
\text { point } \\
(y r)\end{array}$ & Arms & No. & LRC (\%) & DFS $(\%)$ & $\begin{array}{l}\text { Distant-metastasis-free } \\
\text { survival }(\%)\end{array}$ & OS $(\%)$ \\
\hline \multirow[t]{2}{*}{ INT 0099 [24] } & \multirow[t]{2}{*}{1998} & \multirow[t]{2}{*}{ III-IV ${ }^{\mathrm{a}}$} & \multirow[t]{2}{*}{60} & \multirow[t]{2}{*}{5} & RT & 69 & \multirow[t]{2}{*}{ NA } & 29 & \multirow[t]{2}{*}{ NA } & 37 \\
\hline & & & & & $\mathrm{CCRT}+\mathrm{AC}$ & 78 & & 58 & & 67 \\
\hline \multirow[t]{2}{*}{ Chan et al. $[49,61]$} & \multirow[t]{2}{*}{2002} & \multirow{2}{*}{$\begin{array}{l}\text { Ho's } \mathrm{N} 2 / \mathrm{N} 3 \text { or } \\
\text { node } \geq 4 \mathrm{~cm}\end{array}$} & \multirow[t]{2}{*}{66} & \multirow[t]{2}{*}{5} & RT & 176 & \multirow[t]{2}{*}{ NA } & 52 & \multirow[t]{2}{*}{ NA } & 59 \\
\hline & & & & & CCRT & 174 & & 60 & & 70 \\
\hline \multirow[t]{2}{*}{ Lin et al. [54] } & \multirow[t]{2}{*}{2003} & \multirow[t]{2}{*}{ III-IV } & \multirow[t]{2}{*}{65} & \multirow[t]{2}{*}{5} & RT & 143 & \multirow[t]{2}{*}{ NA } & 53 & 70 & 54 \\
\hline & & & & & CCRT & 141 & & 72 & 79 & 72 \\
\hline \multirow[t]{2}{*}{ Kwong et al. [51] } & \multirow[t]{2}{*}{2004} & \multirow{2}{*}{$\begin{array}{r}\text { Ho's } \mathrm{T} 3 \text { or } \mathrm{N} 2 / 3 \\
\text { or node } \geq 4 \mathrm{~cm}\end{array}$} & \multirow[t]{2}{*}{37} & \multirow[t]{2}{*}{3} & RT & 109 & 72 & 58 & 71 & 77 \\
\hline & & & & & CCRT & 110 & 80 & 69 & 85 & 87 \\
\hline \multirow[t]{2}{*}{ Wee et al. [26] } & \multirow[t]{2}{*}{2005} & \multirow[t]{2}{*}{ III-IV } & \multirow[t]{2}{*}{38} & \multirow[t]{2}{*}{2} & RT & 110 & NA & 57 & 70 & 78 \\
\hline & & & & & $\mathrm{CCRT}+\mathrm{AC}$ & 111 & & 75 & 87 & 85 \\
\hline \multirow[t]{2}{*}{ Lee et al. $[25,53]$} & \multirow[t]{2}{*}{2005} & Any $\mathrm{T}, \mathrm{N} 2-3^{\mathrm{b}}$ & 71 & 5 & RT & 176 & 78 & 53 & 68 & 64 \\
\hline & & & & & $\mathrm{CCRT}+\mathrm{AC}$ & 172 & 88 & 62 & 74 & 68 \\
\hline Zhang et al. [43] & 2005 & III-IV ${ }^{b}$ & 24 & 2 & RT & 56 & NA & 83 & 80 & 77 \\
\hline & & & & & CCRT & 59 & & 96 & 92 & 100 \\
\hline Lee et al. [52] & 2006 & $\mathrm{~T} 3-4, \mathrm{~N} 0-1^{\mathrm{b}}$ & 35 & 3 & RT & 49 & 85 & 68 & 81 & 83 \\
\hline & & & & & $\mathrm{CCRT}+\mathrm{AC}$ & 47 & 81 & 73 & 89 & 87 \\
\hline & & & & & $\mathrm{AF}$ & 48 & 78 & 63 & 77 & 73 \\
\hline & & & & & $\mathrm{CCAF}+\mathrm{AC}$ & 50 & 94 & 88 & 97 & 88 \\
\hline Chen et al. [50] & 2008 & III-IV ${ }^{\mathrm{b}}$ & 29 & 2 & RT & 158 & 92 & 73 & 79 & 80 \\
\hline & & & & & $\mathrm{CCRT}+\mathrm{AC}$ & 158 & 98 & 85 & 87 & 90 \\
\hline Chen et al. [9] & 2011 & $\mathrm{II}-\mathrm{III}^{\mathrm{c}}$ & 230 & 5 & $\mathrm{RT}$ & 114 & 91 & 78 & 84 & 86 \\
\hline & & & & & CCRT & 116 & 93 & 88 & 95 & 95 \\
\hline
\end{tabular}

$2 D-R T$ two-dimensional radiotherapy, $C C R T$ concurrent chemoradiation therapy, yrs years, $L R C$ locoregional control, $D F S$ disease-free survival, $O S$ overall survival, $I N T$ intergroup, $R T$ radiotherapy, $A C$ adjuvant chemotherapy, $N A$ not available, $N$ regional lymph node stage, $T$ primary tumor stage, $A F$ accelerated fractionation, $C C A F$ concurrent chemotherapy with accelerated fraction, $M$ distant metastasis stage

${ }^{a}$ AJCC Staging Manual 4th Edition

${ }^{\mathrm{b}}$ AJCC Staging Manual 5th Edition [58]

${ }^{c}$ AJCC Staging Manual 7th Edition [60] 
It is important to note that none of the randomized trials comparing CCRT to RT utilized IMRT (Table 5). Yet, when comparing outcomes of multiple retrospective and prospective studies assessing IMRT, it appears that IMRT is equivalent or better than conventional RT. How much improvement can be attributed to IMRT and/or to the 3D imaging required for IMRT? Perhaps we are better treating tumors near vertebral bodies or critical structures that can only be adequately encompassed by IMRT, or perhaps CTand MRI-based imaging has improved target volume delineation. It is possible that chemotherapy compensates for suboptimal RT techniques, and maybe concurrent chemotherapy with IMRT is enough to treat locally advanced NPC without adjuvant chemotherapy.

While IMRT achieves excellent locoregional control, chemotherapy is still needed to manage undetected micrometastasis. The previously mentioned early IMRT experiences from Lee et al. and Wolden et al. showed moderate distant-metastasis-free rates of 66 and $78 \%$, respectively, despite good locoregional control $[19,22]$. Given that the predominant failure of locally advanced NPC with CCRT is distant metastasis, newer systemic strategies are being studied with the use of IMRT. Two recent phase II trials looked at the addition of targeted agents to CCRT using IMRT. In the first study, Ma et al. [36] used cetuximab with CCRT and found a 2-year distant-failure-free rate of $93 \%$. RTOG 0615, which was a phase II trial looking at the addition of bevacizumab to standard chemoradiation for locally advanced NPC, showed a promising 2-year distantmetastasis-free rate of $91 \%$ [27]. While the delivery of concurrent cisplatin was different, the outcome of distant control appears to be improved compared with the historical rates of $70-80 \%$.

\section{Potential future studies}

As mentioned previously, the different margin sizes from various studies beg the question: what is the optimal margin size? With excellent locoregional control rates from IMRT (Table 1), perhaps our current CTV and PTV margins are too large. In the era of modern imaging and finer resolution, maybe we can reduce the margins and thereby decrease toxicity without compromising outcomes. Furthermore, it is possible that we are unnecessarily treating certain structures that do not improve outcome. One potential area is the sparing of the submandibular glands. Is it safe to spare the submandibular glands even in node positive patients? If so, perhaps we can further preserve salivary function in NPC patients.

Additionally, perhaps we should consider dose-escalating or boosting tumors that are likely to recur locoregionally despite IMRT. Patients with larger primary tumors would be the ideal cohort. With IMRT, it is now possible to further dose-escalate safely.

\section{Conclusions}

In conclusion, IMRT has allowed improved dose delivery to NPC tumors while reducing dose to normal tissues. Many dosimetric and clinical studies of IMRT have shown better treatment plans and clinical outcomes than older techniques. While IMRT is now regularly used for NPC, understanding the technical aspects of treatment planning is needed to maximize the true benefit of this technology.

The treatment for stage I NPC is RT alone while stage II and locally advanced NPC is CCRT. Perhaps IMRT can replace the benefit provided by chemotherapy when added either adjuvantly or concurrently to conventional RT. Future studies should focus on sparing and reducing target volumes in the face of excellent locoregional outcomes while doseescalating for tumors likely to recur.

\section{References}

1. Hunt MA, Zelefsky MJ, Wolden S et al (2001) Treatment planning and delivery of intensity-modulated radiation therapy for primary nasopharynx cancer. Int J Radiat Oncol Biol Phys 49(3):623-632

2. Kam MK, Chau RM, Suen J, Choi PH, Teo PM (2003) Intensitymodulated radiotherapy in nasopharyngeal carcinoma: dosimetric advantage over conventional plans and feasibility of dose escalation. Int J Radiat Oncol Biol Phys 56(1):145-157

3. Xia P, Fu KK, Wong GW, Akazawa C, Verhey LJ (2000) Comparison of treatment plans involving intensity-modulated radiotherapy for nasopharyngeal carcinoma. Int $\mathrm{J}$ Radiat Oncol Biol Phys 48(2):329-337

4. Kam MK, Leung SF, Zee B et al (2007) Prospective randomized study of intensity-modulated radiotherapy on salivary gland function in early-stage nasopharyngeal carcinoma patients. J Clin Oncol 25(31):4873-4879

5. Lee N, Harris J, Garden AS et al (2009) Intensity-modulated radiation therapy with or without chemotherapy for nasopharyngeal carcinoma: radiation therapy oncology group phase II trial 0225. J Clin Oncol 27(22):3684-3690

6. Pow EH, Kwong DL, McMillan AS et al (2006) Xerostomia and quality of life after intensity-modulated radiotherapy vs. conventional radiotherapy for early-stage nasopharyngeal carcinoma: initial report on a randomized controlled clinical trial. Int J Radiat Oncol Biol Phys 66(4):981-991

7. Epstein JB, Emerton S, Kolbinson DA et al (1999) Quality of life and oral function following radiotherapy for head and neck cancer. Head Neck 21(1):1-11

8. Epstein JB, Robertson M, Emerton S, Phillips N, StevensonMoore P (2001) Quality of life and oral function in patients treated with radiation therapy for head and neck cancer. Head Neck 23 (5):389-398

9. Chen QY, Wen YF, Guo L et al (2011) Concurrent chemoradiotherapy vs radiotherapy alone in stage II nasopharyngeal carcinoma: phase III randomized trial. J Natl Cancer Inst 103(23):17611770 
10. Denham JW, Abbott RL (1991) Concurrent cisplatin, infusional fluorouracil, and conventionally fractionated radiation therapy in head and neck cancer: dose-limiting mucosal toxicity. J Clin Oncol 9(3):458-463

11. Sonis ST, Eilers JP, Epstein JB et al (1999) Validation of a new scoring system for the assessment of clinical trial research of oral mucositis induced by radiation or chemotherapy. Mucositis Study Group. Cancer 85(10):2103-2113

12. Eisbruch A, Lyden T, Bradford CR et al (2002) Objective assessment of swallowing dysfunction and aspiration after radiation concurrent with chemotherapy for head-and-neck cancer. Int $\mathrm{J}$ Radiat Oncol Biol Phys 53(1):23-28

13. Mittal BB, Pauloski BR, Haraf DJ et al (2003) Swallowing dysfunction-preventative and rehabilitation strategies in patients with head-and-neck cancers treated with surgery, radiotherapy, and chemotherapy: a critical review. Int J Radiat Oncol Biol Phys 57(5):1219-1230

14. Wu CH, Hsiao TY, Ko JY, Hsu MM (2000) Dysphagia after radiotherapy: endoscopic examination of swallowing in patients with nasopharyngeal carcinoma. Ann Otol Rhinol Laryngol 109 (3):320-325

15. Huang SC, Lui LT, Lynn TC (1985) Nasopharyngeal cancer: study III. A review of 1206 patients treated with combined modalities. Int J Radiat Oncol Biol Phys 11(10):1789-1793

16. Butler EB, Teh BS, Grant WH 3rd et al (1999) Smart (simultaneous modulated accelerated radiation therapy) boost: a new accelerated fractionation schedule for the treatment of head and neck cancer with intensity modulated radiotherapy. Int J Radiat Oncol Biol Phys 45(1):21-32

17. Ling CC, Humm J, Larson S et al (2000) Towards multidimensional radiotherapy (MD-CRT): biological imaging and biological conformality. Int J Radiat Oncol Biol Phys 47(3):551-560

18. Mohan R, Wu Q, Manning M, Schmidt-Ullrich R (2000) Radiobiological considerations in the design of fractionation strategies for intensity-modulated radiation therapy of head and neck cancers. Int J Radiat Oncol Biol Phys 46(3):619-630

19. Lee N, Xia P, Quivey JM et al (2002) Intensity-modulated radiotherapy in the treatment of nasopharyngeal carcinoma: an update of the UCSF experience. Int J Radiat Oncol Biol Phys 53(1):12-22

20. Kwong DL, Pow EH, Sham JS et al (2004) Intensity-modulated radiotherapy for early-stage nasopharyngeal carcinoma: a prospective study on disease control and preservation of salivary function. Cancer 101(7):1584-1593

21. Kam MK, Teo PM, Chau RM et al (2004) Treatment of nasopharyngeal carcinoma with intensity-modulated radiotherapy: the Hong Kong experience. Int J Radiat Oncol Biol Phys 60(5):1440-1450

22. Wolden SL, Chen WC, Pfister DG, Kraus DH, Berry SL, Zelefsky MJ (2006) Intensity-modulated radiation therapy (IMRT) for nasopharynx cancer: update of the Memorial Sloan-Kettering experience. Int J Radiat Oncol Biol Phys 64(1):57-62

23. Kwong DL, Sham JS, Leung LH et al (2006) Preliminary results of radiation dose escalation for locally advanced nasopharyngeal carcinoma. Int J Radiat Oncol Biol Phys 64(2):374-381

24. Al-Sarraf M, LeBlanc M, Giri PG et al (1998) Chemoradiotherapy versus radiotherapy in patients with advanced nasopharyngeal cancer: phase III randomized Intergroup study 0099. J Clin Oncol 16(4):1310-1317

25. Lee AW, Lau WH, Tung SY et al (2005) Preliminary results of a randomized study on therapeutic gain by concurrent chemotherapy for regionally-advanced nasopharyngeal carcinoma: NPC-9901 Trial by the Hong Kong Nasopharyngeal Cancer Study Group. J Clin Oncol 23(28):6966-6975

26. Wee J, Tan EH, Tai BC et al (2005) Randomized trial of radiotherapy versus concurrent chemoradiotherapy followed by adjuvant chemotherapy in patients with American Joint Committee on Cancer/International Union against cancer stage III and IV nasopharyngeal cancer of the endemic variety. J Clin Oncol 23 (27):6730-6738

27. Lee NY, Zhang Q, Pfister DG et al (2012) Addition of bevacizumab to standard chemoradiation for locoregionally advanced nasopharyngeal carcinoma (RTOG 0615): a phase 2 multiinstitutional trial. Lancet Oncol 13(2):172-180

28. Lin S, Lu JJ, Han L, Chen Q, Pan J (2010) Sequential chemotherapy and intensity-modulated radiation therapy in the management of locoregionally advanced nasopharyngeal carcinoma: experience of 370 consecutive cases. BMC Cancer 10:39

29. Lin S, Pan J, Han L, Zhang X, Liao X, Lu JJ (2009) Nasopharyngeal carcinoma treated with reduced-volume intensity-modulated radiation therapy: report on the 3-year outcome of a prospective series. Int J Radiat Oncol Biol Phys 75(4):1071-1078

30. Ng WT, Lee MC, Hung WM et al (2011) Clinical outcomes and patterns of failure after intensity-modulated radiotherapy for nasopharyngeal carcinoma. Int J Radiat Oncol Biol Phys 79(2):420 428

31. Su SF, Han F, Zhao C et al (2012) Long-term outcomes of earlystage nasopharyngeal carcinoma patients treated with intensitymodulated radiotherapy alone. Int J Radiat Oncol Biol Phys 82 (1):327-333

32. Tham IW, Hee SW, Yeo RM et al (2009) Treatment of nasopharyngeal carcinoma using intensity-modulated radiotherapy-the national cancer centre Singapore experience. Int J Radiat Oncol Biol Phys 75(5):1481-1486

33. Wong FC, Ng AW, Lee VH et al (2010) Whole-field simultaneous integrated-boost intensity-modulated radiotherapy for patients with nasopharyngeal carcinoma. Int J Radiat Oncol Biol Phys 76 (1):138-145

34. Xiao WW, Huang SM, Han F et al (2011) Local control, survival, and late toxicities of locally advanced nasopharyngeal carcinoma treated by simultaneous modulated accelerated radiotherapy combined with cisplatin concurrent chemotherapy: long-term results of a phase 2 study. Cancer 117(9):1874-1883

35. Bakst RL, Lee N, Pfister DG et al (2011) Hypofractionated dosepainting intensity modulated radiation therapy with chemotherapy for nasopharyngeal carcinoma: a prospective trial. Int J Radiat Oncol Biol Phys 80(1):148-153

36. Ma BB, Kam MK, Leung SF et al (2012) A phase II study of concurrent cetuximab-cisplatin and intensity-modulated radiotherapy in locoregionally advanced nasopharyngeal carcinoma. Ann Oncol 23(5):1287-1292

37. Xiayun H, Ou D, Ying H, Zhu G, Hu C, Liu T (2011) Experience with combination of cisplatin plus gemcitabine chemotherapy and intensity-modulated radiotherapy for locoregionally advanced nasopharyngeal carcinoma. Eur Arch Otorhinolaryngol 269:10271033

38. Chung NN, Ting LL, Hsu WC, Lui LT, Wang PM (2004) Impact of magnetic resonance imaging versus $\mathrm{CT}$ on nasopharyngeal carcinoma: primary tumor target delineation for radiotherapy. Head Neck 26(3):241-246

39. Liao XB, Mao YP, Liu LZ et al (2008) How does magnetic resonance imaging influence staging according to AJCC staging system for nasopharyngeal carcinoma compared with computed tomography? Int J Radiat Oncol Biol Phys 72(5):1368-1377

40. Tham IW, Lu JJ (2010) Controversies and challenges in the current management of nasopharyngeal cancer. Expert Rev Anticancer Ther 10(9):1439-1450

41. Gregoire V, Levendag P, Ang KK et al (2003) CT-based delineation of lymph node levels and related CTVs in the node-negative neck: DAHANCA, EORTC, GORTEC, NCIC, RTOG consensus guidelines. Radiother Oncol 69(3):227-236

42. Marks LB, Yorke ED, Jackson A, et al. Use of normal tissue complication probability models in the clinic. Int J Radiat Oncol Biol Phys 76(3):S10-S19 
43. Eisbruch A, Ten Haken RK, Kim HM, Marsh LH, Ship JA (1999) Dose, volume, and function relationships in parotid salivary glands following conformal and intensity-modulated irradiation of head and neck cancer. Int J Radiat Oncol Biol Phys 45(3):577-587

44. Blanco AI, Chao KS, El Naqa I et al (2005) Dose-volume modeling of salivary function in patients with head-and-neck cancer receiving radiotherapy. Int J Radiat Oncol Biol Phys 62(4):1055-1069

45. Nutting CM, Morden JP, Harrington KJ et al (2011) Parotidsparing intensity modulated versus conventional radiotherapy in head and neck cancer (PARSPORT): a phase 3 multicentre randomised controlled trial. Lancet Oncol 12(2):127-136

46. Geara FB, Sanguineti G, Tucker SL et al (1997) Carcinoma of the nasopharynx treated by radiotherapy alone: determinants of distant metastasis and survival. Radiother Oncol 43(1):53-61

47. Sanguineti G, Geara FB, Garden AS et al (1997) Carcinoma of the nasopharynx treated by radiotherapy alone: determinants of local and regional control. Int J Radiat Oncol Biol Phys 37(5):985-996

48. Lee AW, Sze WM, Au JS et al (2005) Treatment results for nasopharyngeal carcinoma in the modern era: the Hong Kong experience. Int J Radiat Oncol Biol Phys 61(4):1107-1116

49. Chan AT, Leung SF, Ngan RK et al (2005) Overall survival after concurrent cisplatin-radiotherapy compared with radiotherapy alone in locoregionally advanced nasopharyngeal carcinoma. J Natl Cancer Inst 97(7):536-539

50. Chen Y, Liu MZ, Liang SB et al (2008) Preliminary results of a prospective randomized trial comparing concurrent chemoradiotherapy plus adjuvant chemotherapy with radiotherapy alone in patients with locoregionally advanced nasopharyngeal carcinoma in endemic regions of China. Int J Radiat Oncol Biol Phys 71(5):1356-1364

51. Kwong DL, Sham JS, Au GK et al (2004) Concurrent and adjuvant chemotherapy for nasopharyngeal carcinoma: a factorial study. J Clin Oncol 22(13):2643-2653

52. Lee AW, Tung SY, Chan AT et al (2006) Preliminary results of a randomized study (NPC-9902 Trial) on therapeutic gain by concurrent chemotherapy and/or accelerated fractionation for locally advanced nasopharyngeal carcinoma. Int J Radiat Oncol Biol Phys 66(1):142-151

53. Lee AW, Tung SY, Chua DT et al (2010) Randomized trial of radiotherapy plus concurrent-adjuvant chemotherapy vs radiotherapy alone for regionally advanced nasopharyngeal carcinoma. J Natl Cancer Inst 102(15):1188-1198

54. Lin JC, Jan JS, Hsu CY, Liang WM, Jiang RS, Wang WY (2003) Phase III study of concurrent chemoradiotherapy versus radiotherapy alone for advanced nasopharyngeal carcinoma: positive effect on overall and progression-free survival. J Clin Oncol 21(4):631637

55. Zhang L, Zhao C, Peng PJ et al (2005) Phase III study comparing standard radiotherapy with or without weekly oxaliplatin in treatment of locoregionally advanced nasopharyngeal carcinoma: preliminary results. J Clin Oncol 23(33):8461-8468

56. Baujat B, Audry H, Bourhis J et al (2006) Chemotherapy in locally advanced nasopharyngeal carcinoma: an individual patient data meta-analysis of eight randomized trials and 1753 patients. Int $\mathbf{J}$ Radiat Oncol Biol Phys 64(1):47-56

57. Kam M, Leung S, Yu K et al (2010) Long-term treatment outcome of nasopharyngeal carcinoma (NPC) using intensity-modulated radiotherapy (IMRT). J Clin Oncol 28(15S): Abstract 5582

58. Fleming ID, Cooper J, Henson DE et al (1997) AJCC cancer staging manual, 5th edn. Lippincott-Raven, Philadelphia

59. Greene FL, Page DL, Fleming ID et al (2002) AJCC cancer staging manual, 6th edn. Springer, New York

60. Edge SB, Byrd DR, Compton CC, Fritz AG, Greene FL, Trotti A (2010) American Joint Committee on Cancer Staging Manual, 7th edn. Springer, New York

61. Chan AT, Teo PM, Ngan RK et al (2002) Concurrent chemotherapyradiotherapy compared with radiotherapy alone in locoregionally advanced nasopharyngeal carcinoma: progression-free survival analysis of a phase III randomized trial. J Clin Oncol 20(8):2038-2044 